\title{
Infection Heterogeneity and Microbiota Differences in Chicks Infected by Salmonella enteritidis
}

\author{
Shu Wu ${ }^{1,2}{ }^{\oplus}$, Guanglei Cong ${ }^{2}$, Qianyun Zhang $\left.{ }^{2}{ }^{(}\right)$, Hong Yao ${ }^{2}$, Zhenxin Wang ${ }^{2}$, Kelang Kang ${ }^{1,2} \mathbb{D}, \mathrm{Xi}_{\mathrm{H}} \mathrm{He}^{1, *}$ and \\ Shourong Shi $2,3,4, *$ (i)
}

Citation: Wu, S.; Cong, G.; Zhang, Q.; Yao, H.; Wang, Z.; Kang, K.; He,

X.; Shi, S. Infection Heterogeneity and Microbiota Differences in Chicks Infected by Salmonella enteritidis. Microorganisms 2021, 9, 1705.

https://doi.org/10.3390/

microorganisms 9081705

Academic Editor: Chao-Nan Lin

Received: 1 July 2021

Accepted: 5 August 2021

Published: 11 August 2021

Publisher's Note: MDPI stays neutral with regard to jurisdictional claims in published maps and institutional affiliations.

Copyright: (c) 2021 by the authors. Licensee MDPI, Basel, Switzerland. This article is an open access article distributed under the terms and conditions of the Creative Commons Attribution (CC BY) license (https:/ / creativecommons.org/licenses/by/ $4.0 /)$.
1 College of Animal Science and Technology, Hunan Agricultural University, Changsha 410128, China; wushu223759@163.com (S.W.); kangkelang@126.com (K.K.)

2 Department of Feed and Nutrition, Poultry Institute, Chinese Academy of Agricultural Sciences, Yangzhou 225125, China; MZ120181027@yzu.edu.cn (G.C.); zhangqy1120@163.com (Q.Z.);

Ravenpeach@163.com (H.Y.); wangzhenxin1995@163.com (Z.W.)

3 Institute of Effective Evaluation of Feed and Feed Additive (Poultry Institute), Ministry of Agriculture, Yangzhou 225125, China

4 Jiangsu Co-Innovation Center for the Prevention and Control of Important Animal Infectious Disease and Zoonose, Yangzhou University, Yangzhou 225009, China

* Correspondence: hexi111@126.com (X.H.); ssr236@163.com (S.S.)

\begin{abstract}
This study was conducted to compare the infection heterogeneity and cecal microbiota in chicks infected by S. enteritidis. Forty-eight 8-d-old female Arbor Acres chicks were challenged with S. enteritidis and euthanized $24 \mathrm{~h}$ later. The eight chicks with the highest Salmonella tissue loads were assigned to group S (S. enteritidis-susceptible), and the eight chicks with the lowest Salmonella tissue loads were assigned to group $\mathrm{R}$ (S. enteritidis-resistant). Chicks in group S showed a higher liver index $(p<0.05)$, obvious liver lesions, and an decreasing trend for the villus height-to-crypt depth ratio $(p<0.10)$, compared with those in group R. Gene expression of occludin, MUC2, and IL10 was higher, whereas that of $i N O S$ and IL6 was lower $(p<0.05)$, in chicks of group R relative to those in group S. Separation of the cecal microbial community structure has been found between the two groups. The S. enteritidis-susceptible chicks showed higher abundance of pathogenic bacteria (Fusobacterium and Helicobacter) in their cecal, while Desulfovibrio_piger was enriched in the cecal of S. enteritidis-resistant chicks. In summary, chicks showed heterogeneous responses to S. enteritidis infection. Enhanced intestinal barrier function and cecal microbiota structure, especially a higher abundance of Desulfovibrio_piger, may help chicks resist S. enteritidis invasion.
\end{abstract}

Keywords: Salmonella enteritidis; heterogeneity; cecal microbiome; intestinal barrier; Desulfovibrio_piger

\section{Introduction}

Salmonella is a major foodborne pathogen of global importance, which has led to large numbers of deaths in humans and caused economic losses in animal husbandry [1]. Among the more than 2500 identified Salmonella enterica serotypes, Salmonella enteritidis (S. enteritidis) is the most frequently spread from animals to humans globally [2]. S. enteritidis has caused occasional epidemic outbreaks around the world, such as in China [3], South Africa [4] and the United States [5]. Poultry are the primary S. enteritidis host, and the percent prevalence of $S$. enteritidis in chicken meat is strongly positively correlated ( $r=0.804, p \leq 0.01$ ) with the incidence of human illnesses caused by this serotype [6]. These observations highlight the importance of studying $S$. enteritidis infection in poultry for reasons associated with both public health and poultry production.

Host susceptibility to pathogen infection is frequently heterogeneous [7], as demonstrated by the phenomenon of the median lethal dose (lethal dose 50 [LD $\left.\mathrm{LD}_{50}\right]$ ), which describes the microbe dose that will kill only $50 \%$ of a test population [8]. Poultry infected with $S$. enteritidis may suffer systemic infection that can potentially lead to death, or may 
evolve into a long-term asymptomatic carrier-state [9]. Several studies have confirmed that heterogeneous responses to Salmonella infection can be partly explained by the genetic background and immune function status of the host $[10,11]$. However, numerous studies have also reported the phenomenon of heterogeneous bacterial shedding (super-shedders and low-shedders) in genetically homogeneous host populations [12,13], suggestive of the existence of additional factors that can influence the susceptibility and resistance of individuals to Salmonella colonization. Over recent years, the composition of the intestinal microbiota has been increasingly associated with heterogeneous host responses to pathogen infection [14-16].

The intestinal microbiota comprises a complex bacterial community and maintaining a mutually beneficial balance between the host and the gut microflora is very important for human health $[17,18]$. Intestinal dysbiosis can promote or even directly lead to a variety of conditions, including inflammatory diseases, colon cancer, and autoimmune disorders [19]. Pathogen infection is also closely related to the intestinal microbiota. Pathogen infection can lead to an imbalance in the intestinal environment, where pathogen growth is favored over that of probiotics [20-22]. Conversely, the gut microbiota can help inhibit pathogen colonization $[23,24]$. Although various mechanisms through which gut microbiota can protect the host against intestinal infection have been described, it remains unclear whether the heterogeneous responses of poultry to $S$. enteritidis infection are related to subtle changes in gut microbiota composition. In this study, we investigated the infection of S. enteritidis-susceptible and -resistant chicks from the aspects of tissue lesions, intestinal health and inflammatory response, and analyzed their cecal microbiota differences.

\section{Materials and Methods}

\subsection{Ethical Statement}

The study was conducted according to the Regulations of the Experimental Animal Administration issued by the State Committee of Science and Technology of the People's Republic of China. The animal use protocol was approved by the Animal Care and Use Committee of the Poultry Institute, Chinese Academy of Agriculture Science (No. CNP20201030).

\subsection{Animal Management}

Forty-eight 1-d-old Arbor Acres (AA) broiler chicks were obtained from Jiangsu Jinghai Poultry Industry Group Co., Ltd. (Nantong, Jiangsu, China). Cloacal swab tests [25] were carried out immediately after hatching to exclude Salmonella infection. The chicks were reared in cages with a wire screen floor. Water and feed were provided ad libitum, with the photoperiod set at $24 \mathrm{~L}$ throughout the study. The temperature in the broiler house during the first week ranged from 32 to $35^{\circ} \mathrm{C}$, and was then decreased by $1{ }^{\circ} \mathrm{C} \mathrm{d}^{-1}$ until reaching the final temperature of $30^{\circ} \mathrm{C}$ on $\mathrm{d} 9$. The diet of the chicks, without antibiotics or anticoccidial drugs and negative for Salmonella, was formulated to meet or slightly exceed all nutrient requirements (NRC, 1994) and was prepared at the Poultry Institute, Chinese Academy of Agriculture Science. The nutrient composition is shown in Table 1.

\subsection{Challenge with S. enteritidis}

Forty-eight chicks were orally gavaged with $1 \times 10^{9}$ colony forming unit (CFU) of $S$. enteritidis at d 8 as previously described [1,26,27]. Briefly, the $S$. enteritidis strain CMCC(B)50041 (Bei Na Chuanglian Biotechnology Co., Ltd., Suzhou, Jiangsu, China) were grown in modified Martin medium (Qingdao-Hope Biotechnology Co., Ltd., Qingdao, China) overnight at $37^{\circ} \mathrm{C}$ with constant shaking. Before inoculation, the bacteria were washed with PBS, and serially diluted to a concentration of $1 \times 10^{9} \mathrm{CFU} / \mathrm{mL}$ based on the optical density at $600 \mathrm{~nm}$ measured by a microplate reader (Infinite M200 Pro, Tecan, Switzerland). The bacterial stock was kept on ice before infection. After infection, the same bacterial stock was plated on xylose lysine desoxycholate (XLD) agar (Qingdao-Hope Biotechnology Co., Ltd., Qingdao, China) to verify the CFU accuracy. 
Table 1. Diet composition and nutrient levels (as-fed basis) from 1 to $9 \mathrm{~d}$ of age.

\begin{tabular}{cc}
\hline Ingredient & $\%$ \\
\hline Corn & 55.24 \\
Soybean meal (46\%) & 36.92 \\
Soybean oil & 3.50 \\
Limestone & 1.12 \\
Calcium hydrogen phosphate & 2.10 \\
Methionine & 0.28 \\
Lysine (98\%) & 0.22 \\
NaCl & 0.30 \\
Vitamin premix 1 & 0.03 \\
Mineral premix ${ }^{2}$ & 0.20 \\
Choline chloride (70\%) & 0.09 \\
Total & 100.00 \\
Nutrient levels (\%) & \\
ME (kcal/kg) & 2950 \\
CP & 21.00 \\
Ca & 1.00 \\
Total phosphorus & 0.67 \\
Nonphytate phosphorous & 0.45 \\
Digestible Lys & 1.20 \\
Digestible Thr & 0.85 \\
Digestible Trp & 0.66 \\
Digestible sulfur-containg acid & 0.22 \\
\hline
\end{tabular}

${ }^{1}$ Premix vitamin provided per kilogram of diet: Vitamin A (retinyl palmitate), $8000 \mathrm{IU}$; vitamin D3 (cholecalciferol), $1000 \mathrm{IU}$; vitamin E (D, L- $\alpha$-tocopheryl acetate), $20 \mathrm{IU}$; vitamin K3 (menadione sodium bisulfate complex), $0.50 \mathrm{mg}$; vitamin B1, $2.00 \mathrm{mg}$; vitamin B2, $8.00 \mathrm{mg}$; vitamin B6, $3.50 \mathrm{mg}$; vitamin B12 (cobalamin), $10.00 \mu \mathrm{g}$; niacin, $35.00 \mathrm{mg}$; calcium pantothenic, $10.00 \mathrm{mg}$; folic acid, $0.55 \mathrm{mg}$; biotin, $0.18 \mathrm{mg}$. ${ }^{2}$ Premix mineral provided per kilogram of diet: Fe, $80.00 \mathrm{mg}$; Mn, $100.00 \mathrm{mg}$; Zn, $80.00 \mathrm{mg}$; I, $0.70 \mathrm{mg}$; Se, $0.30 \mathrm{mg}$; Cu, $8.00 \mathrm{mg}$. ${ }^{3} \mathrm{ME}$ was a calculated value, whereas the other nutrient levels were measured values.

\subsection{Sample Collection}

At $24 \mathrm{~h}$ post infection (hpi) (age $=9 \mathrm{~d}$ ), all the chicks were euthanized by severing the jugular vein. The body weight, liver weight and spleen weight were measured, and index of liver and spleen were calculated. About 0.2 0.4 $\mathrm{g}$ of liver and a half of the spleen were collected aseptically from each chick and stored at $4{ }^{\circ} \mathrm{C}$ for Salmonella load quantification. The cecal content was collected, frozen in liquid nitrogen, and stored at $-80^{\circ} \mathrm{C}$ for $16 \mathrm{~S}$ rRNA sequencing analysis. Small segments of the rest liver, spleen, and jejunum were collected and immediately fixed in a 10\% formaldehyde solution for histopathological examination. In addition, cecal tonsil and segments of jejunum were collected, frozen in liquid nitrogen, and stored at $-80^{\circ} \mathrm{C}$ for quantification of target gene mRNA levels.

\subsection{Salmonella Load Measurement and Sample Grouping}

To determine the Salmonella loads in the liver and spleen, the samples were weighed and diluted in $3 \mathrm{~mL}$ of sterile PBS. Then, the samples were homogenized for $120 \mathrm{~s}$ at $60 \mathrm{~Hz}$ using a SCIENTZ-48 homogenizer (Ningbo Xingzhi Biotechnology Co., Ltd., Ningbo, China). A total of $50 \mu \mathrm{L}$ of the homogenate liquid from the samples was plated on XLD agar and incubated for $24 \mathrm{~h}$ at $37^{\circ} \mathrm{C}$. According to the result of spleen Salmonella loads $\left(\log _{10} \mathrm{CFU} / \mathrm{g}\right)$, we select $\log _{10} \mathrm{CFU} / \mathrm{g}>4.400$ as the cut-off value for $\mathrm{S}$. Enteritidis-resistant chicks, and $\log _{10} \mathrm{CFU} / \mathrm{g}<2.700$ as the cut-off value for S. enteritidis-susceptible chicks. According to the cut-off values, eight chicks were assigned to group $\mathrm{S}$, and eight chicks were assigned to group $\mathrm{R}$ (Table S1).

\subsection{Liver and Spleen Histopathology and Intestinal Morphology Determination}

Tissue histopathology and intestinal morphology of chicks from both groups were determined as previously described [28,29]. Briefly, small segments of liver, spleen, and middle jejunum were fixed in $10 \%$ buffered formaldehyde $(\mathrm{pH} 7.2)$ and dehydrated via an ascending ethanol gradient. After xylene clearing, the samples were embedded in paraffin and processed into 5 - $\mu \mathrm{m}$-thick slices followed by mounting and hematoxylin-eosin (HE) staining. Inflammatory infiltration and general damage in the liver and spleen, as well as 
the villus height $(\mathrm{VH})$ and crypt depth $(\mathrm{CD})$ of the jejunum, were observed and measured under a fluorescence microscope (DM4000B, Leica Microsystems, Wetzlar, Germany). The ratio of the villus height-to-crypt depth (VCR) was also calculated. Histopathological images of liver or spleen were scored by a pathology professional who did not know the experimental group according to the number of inflammatory cell nodules and the degree of cell degeneration and necrosis. The score from normal to severe lesions was $0 \sim 4$.

\subsection{RNA Isolation and Quantitative Real-Time PCR}

Total RNA was extracted from the cecal tonsil or middle jejunum of birds from both groups using an RNAsimple Total RNA Kit (Tiangen Biotech Co., Ltd., Beijing, China) following the manufacturer's instructions. RNA concentration and purity were determined by measuring the absorbance at 260 and $280 \mathrm{~nm}$ using a NanoDrop 2000 spectrophotometer (Thermo Fisher Scientific, Rockford, IL, USA), and RNA quality was assessed by agarose gel electrophoresis. Total RNA was reverse-transcribed using the FastKing gDNA Dispelling RT SuperMix Kit (Tiangen Biotech Co., Ltd.) in accordance with the manufacturer's instructions. Reverse transcription was performed at $42{ }^{\circ} \mathrm{C}$ for $15 \mathrm{~min}$ followed by heat inactivation for $3 \mathrm{~min}$ at $95^{\circ} \mathrm{C}$. The cDNA was stored at $-20^{\circ} \mathrm{C}$ until further use. Real-time quantitative PCR was performed in a StepOnePlusTM Real-Time PCR System (Applied Biosystems, Foster City, CA, USA) following optimized PCR protocols using a SuperReal PreMix Plus (SYBR Green) Kit (Tiangen Biotech Co., Ltd.). The protocol consisted of an initial denaturation step at $95{ }^{\circ} \mathrm{C}$ for $15 \mathrm{~min}$, followed by 40 cycles of $10 \mathrm{~s}$ denaturation at $95^{\circ} \mathrm{C}$ and $30 \mathrm{~s}$ annealing/extension at $60^{\circ} \mathrm{C}$, with a final step at $95^{\circ} \mathrm{C}$ for $15 \mathrm{~s}$. The primers for inducible nitric oxide synthase (iNOS), interferon-gamma (IFNG), tumor necrosis factoralpha (TNFA), interleukin 1 beta (IL1B), IL6, IL8, IL10, occludin, claudin, zonula occluden 1 (ZO-1), mucin 2 (MUC2), and glyceraldehyde-3-phosphate dehydrogenase (GAPDH) are listed in Table 2. The $\triangle \triangle \mathrm{Ct}$ method was used to estimate mRNA abundance. GAPDH was used as the internal reference gene, and the mRNA expression of target genes was normalized to that of GAPDH.

Table 2. Gene-specific primers for related genes.

\begin{tabular}{|c|c|c|c|c|}
\hline Gene & GenBank Accession No. & Primer Orientation & Primer Sequence $\left(5^{\prime} \rightarrow 3^{\prime}\right)$ & Product Size (bp) \\
\hline GAPDH & NM_204305.1 & $\begin{array}{l}\text { Forward } \\
\text { Reverse }\end{array}$ & $\begin{array}{l}\text { GCCCAGAACATCATCCCA } \\
\text { CGGCAGGTCAGGTCAACA }\end{array}$ & 137 \\
\hline iNOS & NM_204961.1 & $\begin{array}{l}\text { Forward } \\
\text { Reverse }\end{array}$ & $\begin{array}{c}\text { CCTGGAGGTCCTGGAAGAGT } \\
\text { CCTGGGTTTCAGAAGTGGC }\end{array}$ & 82 \\
\hline IFNG & NM_205149.1 & $\begin{array}{l}\text { Forward } \\
\text { Reverse }\end{array}$ & $\begin{array}{l}\text { CAAGCTCCCGATGAACGACTT } \\
\text { AGTTGAGCACAGGAGGTCAT }\end{array}$ & 162 \\
\hline TNFA & NM_204267.1 & $\begin{array}{l}\text { Forward } \\
\text { Reverse }\end{array}$ & $\begin{array}{l}\text { CAGGACAGCCTATGCCAACAAG } \\
\text { GGTTACAGGAAGGGCAACTCATC }\end{array}$ & 114 \\
\hline$I L 1 B$ & NM_204524.1 & $\begin{array}{l}\text { Forward } \\
\text { Reverse }\end{array}$ & $\begin{array}{l}\text { CCGAGGAGCAGGGACTTT } \\
\text { AGGACTGTGAGCGGGTGT }\end{array}$ & 133 \\
\hline IL6 & NM_204628.1 & $\begin{array}{l}\text { Forward } \\
\text { Reverse }\end{array}$ & $\begin{array}{l}\text { TTTATGGAGAAGACCGTGAGG } \\
\text { TGTGGCAGATTGGTAACAGAG }\end{array}$ & 106 \\
\hline IL8 & NM_205498.1 & $\begin{array}{l}\text { Forward } \\
\text { Reverse }\end{array}$ & $\begin{array}{l}\text { ATGAACGGCAAGCTTGGAGCTG } \\
\text { TCCAAGCACACCTCTCTTCCATCC }\end{array}$ & 233 \\
\hline IL10 & NM_001004414.2 & $\begin{array}{l}\text { Forward } \\
\text { Reverse }\end{array}$ & $\begin{array}{l}\text { GCTGAGGGTGAAGTTTGAG } \\
\text { CAGGTGAAGAAGCGGTGA }\end{array}$ & 272 \\
\hline occludin & NM_205128.1 & $\begin{array}{l}\text { Forward } \\
\text { Reverse }\end{array}$ & $\begin{array}{l}\text { TCATCGCCTCCATCGTCTAC } \\
\text { TCTTACTGCGCGTCTTCTGG }\end{array}$ & 141 \\
\hline claudin & NM_001013611 & $\begin{array}{l}\text { Forward } \\
\text { Reverse }\end{array}$ & $\begin{array}{c}\text { CTGATTGCTTCCAACCAG } \\
\text { CAGGTCAAACAGAGGTACAAG }\end{array}$ & 140 \\
\hline $\mathrm{ZO}-1$ & XM_413773 & $\begin{array}{l}\text { Forward } \\
\text { Reverse }\end{array}$ & $\begin{array}{c}\text { CTTCAGGTGTTTCTCTTCCTCCTC } \\
\text { CTGTGGTTTCATGGCTGGATC }\end{array}$ & 131 \\
\hline MUC2 & NM_001318434.1 & $\begin{array}{l}\text { Forward } \\
\text { Reverse }\end{array}$ & $\begin{array}{l}\text { GTGAAGACCCTGATGAAA } \\
\text { GTGAACACTGGCGAGAAT }\end{array}$ & 219 \\
\hline
\end{tabular}




\subsection{DNA Extraction and Sequencing Library Construction}

Genomic DNA was extracted from homogenized cecal content using CTAB method [30] and stored at $-20^{\circ} \mathrm{C}$. DNA concentration and purity were assessed by $2 \%$ agarose gel electrophoresis and diluted to $1 \mathrm{ng} / \mu \mathrm{L}$ using sterile water. The $\mathrm{V} 4$ region of the bacterial $16 \mathrm{~S}$ rRNA gene was PCR amplified using the barcoded 515F/806R primer pair [31]. Amplicons consisting of around 400-450 bp were extracted and used for further analysis [32,33]. PCR products were purified using the QIAquick Gel Extraction Kit (Qiagen Inc., Santa Clara, CA, USA). Sequencing libraries were generated using the Illumina TruSeq ${ }^{\circledR}$ DNA PCR-Free Sample Preparation Kit (Illumina, San Diego, CA, USA) following the manufacturer's recommendations. After Qubit-based quantification and library qualification, the library was subjected to sequencing at Novogene Co., Ltd. (Beijing, China) using the Illumina NovaSeq6000 platform.

\subsection{Quality Filtering and Sequence Analysis}

Raw Illumina paired-end reads were trimmed of barcodes and primers and combined using Flash software (V1.2.7, http:/ / ccb.jhu.edu/software/FLASH/, accessed on 1 February 2021) with default parameters [34]. The obtained raw sequence data were quality-filtered using QIIME V1.9.1 (http: / / qiime.org/scripts / split_libraries_fastq.html, accessed on 1 February 2021) to obtain effective tags [35]. OTU were assigned at $97 \%$ identity using Uparse V7.0.1001 (http:/ / www.drive5.com/uparse/, accessed on 1 February 2021) based on the effective tags [36]. OTU taxonomic information was annotated by RDP Classifier using a $0.8 \sim 1$ confidence threshold for taxonomic assignment $[37,38]$. Alpha and beta diversity and the significance of taxonomic differences between samples were estimated by QIIME (V1.9.1) and linear discriminant analysis effect size (LEfSe) as previously described [38-40].

\subsection{Statistical Analysis}

Statistical analyses were carried out with SPSS for Windows V22.0 (SPSS Inc., Chicago, IL, USA). Differences between two groups were tested by independent samples $t$-tests and the Wilcoxon rank-sum test. Data are expressed as means \pm SEM. A $p$-value $<0.05$ was considered statistically significant [26].

\section{Results}

3.1. Body Weight, Tissue Index, and Salmonella Loads of S. enteritidis-Susceptible and-Resistant Chicks

The differences in body weight, tissue indices, and Salmonella loads between S. enteritidis-susceptible and -resistant chicks are summarized in Table 3. The liver index, liver Salmonella load, and spleen Salmonella load of S. enteritidis-susceptible chicks (group S) were higher than those of $S$. enteritidis-resistant chicks (group R) $(p<0.05)$ at 24 hpi; however, there was no significant difference in body weight or spleen index between the two groups.

Table 3. Body weight, tissue index ${ }^{1}$, and Salmonella loads of S. enteritidis-susceptible and -resistant chicks ${ }^{2}$.

\begin{tabular}{|c|c|c|c|}
\hline Items & Group $S^{3}$ & Group $\mathbf{R}^{3}$ & $p$-Value \\
\hline $\mathrm{BW}(\mathrm{g})$ & $229.40 \pm 7.47$ & $230.88 \pm 5.47$ & 0.875 \\
\hline Liver Index (\%) & $0.043 \pm 0.001^{\mathrm{a}}$ & $0.038 \pm 0.001^{b}$ & 0.006 \\
\hline Spleen Index (\%) & $0.024 \pm 0.002$ & $0.020 \pm 0.001$ & 0.158 \\
\hline Liver Salmonella loads ( $\left.\log _{10} \mathrm{CFU} / \mathrm{g}\right)$ & $2.750 \pm 0.405^{\mathrm{a}}$ & $1.152 \pm 0.435^{b}$ & 0.018 \\
\hline Spleen Salmonella loads ( $\log _{10}$ CFU/g) & $4.784 \pm 0.100^{\mathrm{a}}$ & $2.491 \pm 0.055^{b}$ & $<0.001$ \\
\hline
\end{tabular}

\footnotetext{
1 Tissue index: Percent of tissue weight relative to body weight. ${ }^{2}$ Results are expressed as means \pm SEM, with $n=8$ per group.

${ }^{3}$ Group S = selected S. enteritidis-susceptible chicks; Group R = selected S. enteritidis-resistant chicks. ${ }^{\text {a,b }}$ In the same row, values with different letters are significantly different between two groups $(p<0.05)$.
} 


\subsection{Liver and Spleen Histopathology of S. enteritidis-Susceptible and -Resistant Chicks}

The differences in liver and spleen histopathology between S. enteritidis-susceptible and -resistant chicks are shown in Figure 1. There were only slight pathological changes in the livers of the birds in group R, with only limited infiltration of heterophilic cells and lymphocytes being observed around some of the blood vessels (Figure 1a,e). In contrast, chicks in group $S$ showed obvious lesions in their livers, including numerous lymphocyte nodules and infiltrated heterophilic cells, as well as pyknosis of liver nuclei (Figure 1b,e). No obvious pathological changes were found in the spleens of chicks in the two groups (Figure 1c,d).

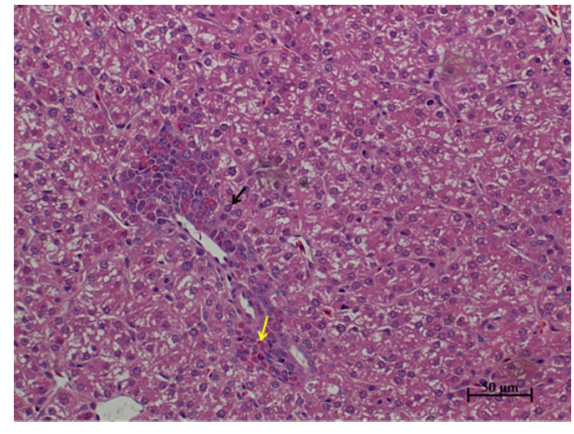

(a)

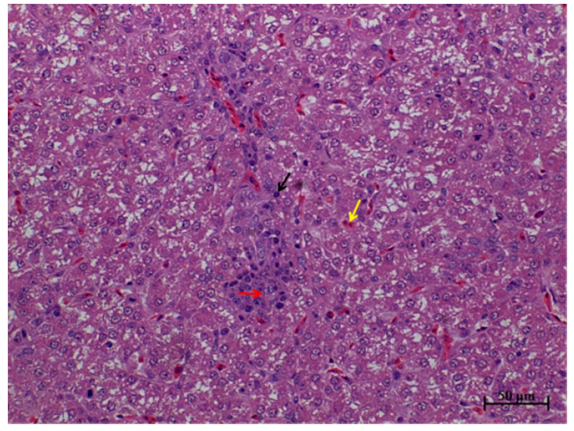

(b)

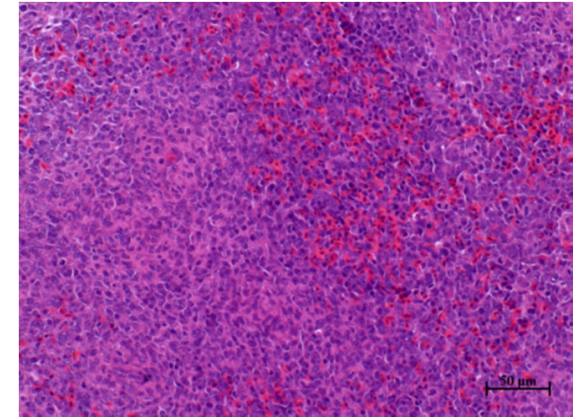

(c)

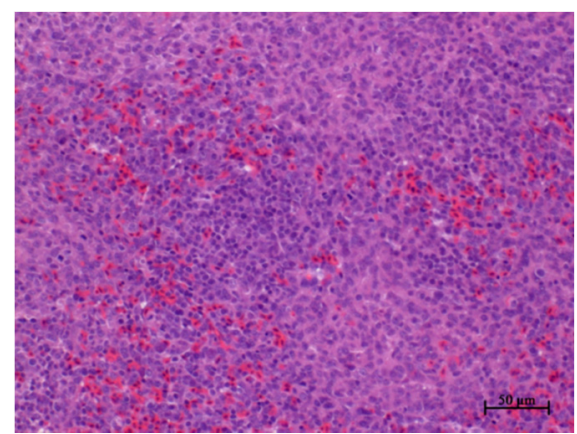

(d)

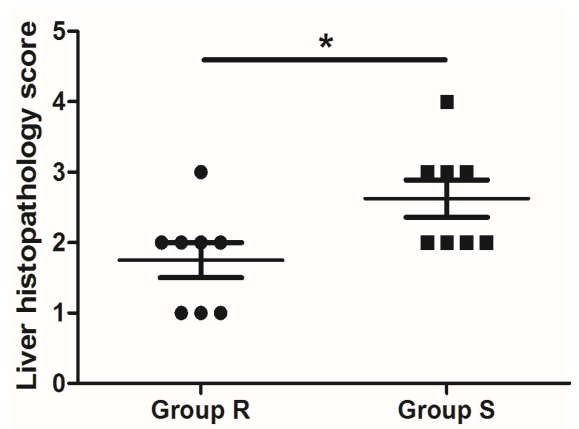

(e)

Figure 1. Histopathology of S. enteritidis-resistant and S. enteritidis-susceptible chicks. (a) Representative liver histopathology of S. enteritidis-resistant chicks (HE staining); (b) Representative liver histopathology of S. enteritidis-susceptible chicks (HE staining); (c) Representative spleen histopathology of S. enteritidis-resistant chicks (HE staining); (d) Representative spleen histopathology of $S$. enteritidis-susceptible chicks (HE staining). Original magnification, $\times 200$. Black arrows indicate the lymphocytes, yellow arrows indicate the heterophilic cells, and red arrows indicate the lymphocyte nodules in liver tissue. Scale bar $=50 \mu \mathrm{m}$. (e) Liver histopathology score of $S$. enteritidis-resistant and -susceptible chicks, $n=8$ per group, Result of significance test was $p<0.05$ when marked *.

\subsection{Intestinal Morphology and Barrier Function of S. enteritidis-Susceptible and-Resistant Chicks}

The differences in jejunum morphology between the S. enteritidis-susceptible and -resistant chicks are summarized in Table 4. Although the chicks in group $\mathrm{R}$ showed lower $\mathrm{CD}$, higher $\mathrm{VH}, \mathrm{VCR}$, and muscle thickness (MT), the differences between the two groups were not statistically significant. Only the VCR showed a higher trend in group $\mathrm{R}(p<0.10)$.

Table 4. Jejunum morphology of S. enteritidis-susceptible and -resistant chicks ${ }^{1}$.

\begin{tabular}{cccc}
\hline Items & Group S & Group R & $p$-Value \\
\hline Villus height $(\mu \mathrm{m})$ & $1084.62 \pm 35.20$ & $1125.93 \pm 90.23$ & 0.683 \\
Crypt depth $(\mu \mathrm{m})$ & $149.56 \pm 7.48$ & $131.55 \pm 16.28$ & 0.348 \\
Ratio of villus height-to-crypt depth & $7.32 \pm 0.34$ & $8.94 \pm 0.75$ & 0.090 \\
Muscle thickness $(\mu \mathrm{m})$ & $117.86 \pm 7.09$ & $118.02 \pm 14.37$ & 0.992 \\
\hline
\end{tabular}

${ }^{1}$ Results are expressed as means \pm SEM, with $n=8$ per group. ${ }^{2}$ Group $\mathrm{S}=$ selected S. enteritidis-susceptible chicks; Group R = selected

S. enteritidis-resistant chicks. 
We further investigated the differences in barrier function between $S$. enteritidissusceptible and -resistant chicks by comparing their expression of the claudin, occludin, ZO-1, and MUC2 genes in the jejunum. As shown in Figure 2a, the expression of occludin and MUC2 was lower in the jejunum of S. enteritidis-susceptible chicks than in that of $S$. enteritidis-resistant chicks $(p<0.05)$. No statistically significant differences in claudin or ZO-1 expression were found between the two groups.

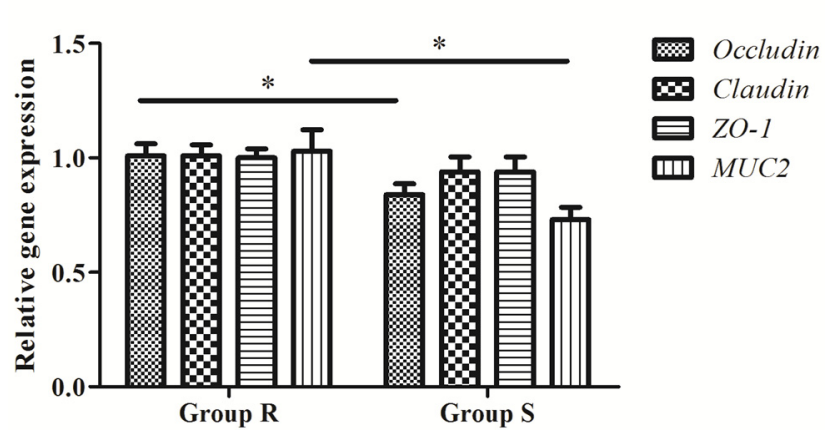

(a)

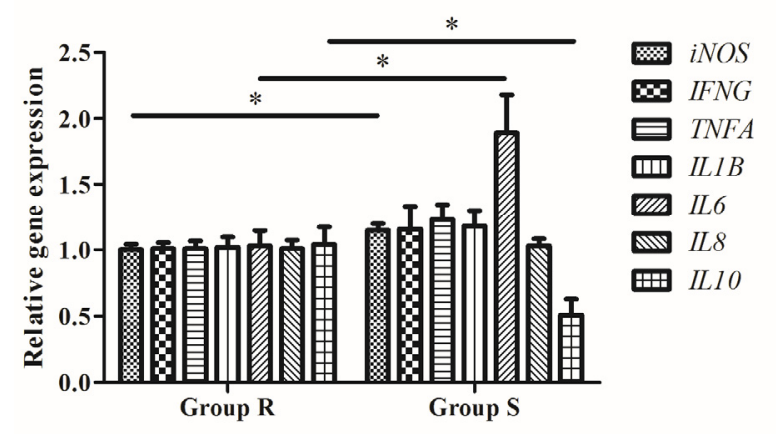

(b)

Figure 2. Relative expression of genes coding for tight junction proteins in the jejunum and inflammatory cytokines in cecal tonsil. (a) Gene expression levels of occludin, claudin, ZO-1, and MUC2 in the jejunum of chicks in group R and group S; (b) Gene expression levels of NOS, IFNG, TNFA, IL1B, IL6, IL8, and IL10 in the cecal tonsil of chicks in group R and group S. Data are presented as means $\pm \operatorname{SEM}(n=8)$. The asterisk $\left(^{*}\right)$ indicates a significant difference between two groups $(p<0.05)$.

\subsection{Expression of Inflammatory Cytokine-Related Genes in S. enteritidis-Susceptible and -Resistant Chicks}

The gene expression of $i N O S, I F N G, T N F A, I L 1 B, I L 6, I L 8$, and IL10 in the cecal tonsil of both groups of chicks are shown in Figure $2 \mathrm{~b}$. Compared with group $\mathrm{R}$, the expression of the genes encoding the proinflammatory factors iNOS and IL6 were markedly higher in the chicks of group S, whereas that of IL10, encoding an anti-inflammatory factor, was significantly lower $(p<0.05)$.

\subsection{Composition and Diversity of Cecal Microorganisms in S. enteritidis-Susceptible and -Resistant Chicks}

A total of 857,129 effective reads were obtained from 16 cecal digesta samples (8 samples per group), and these reads were assigned to 2458 operational taxonomic units (OTU) (Table S2). Each sample contained 53,571 \pm 1632 (mean \pm SEM) effective reads and $694 \pm 46$ (mean \pm SEM) OTU on average. Good's coverage indices were greater than $99.5 \%$ for all the cecal digesta samples (Table S2) and rarefaction curves based on the observed OTU reached a plateau (Figure S1), both indicating that sequencing coverage was sufficient to represent all OTU present in the samples.

No significant difference was found in microbial community richness and diversity between the $S$. enteritidis-susceptible and -resistant chicks by alpha diversity analysis, including ACE, Chao1, PD_whole_tree, Shannon, and Simpson indices (Table S3). However, beta diversity analysis indicated there was a separation of the cecal microbial community structure between the $S$. enteritidis-susceptible and -resistant chicks, as illustrated by principal component analysis (PCA), non-metric multidimensional scaling (NMDS), and unweighted pair-group method with arithmetic mean (Figure 3). The beta diversity of group $\mathrm{R}$ was lower than that of group $\mathrm{S}$ as calculated by binary_jaccard and unweighted_unifrac (Table S4). 


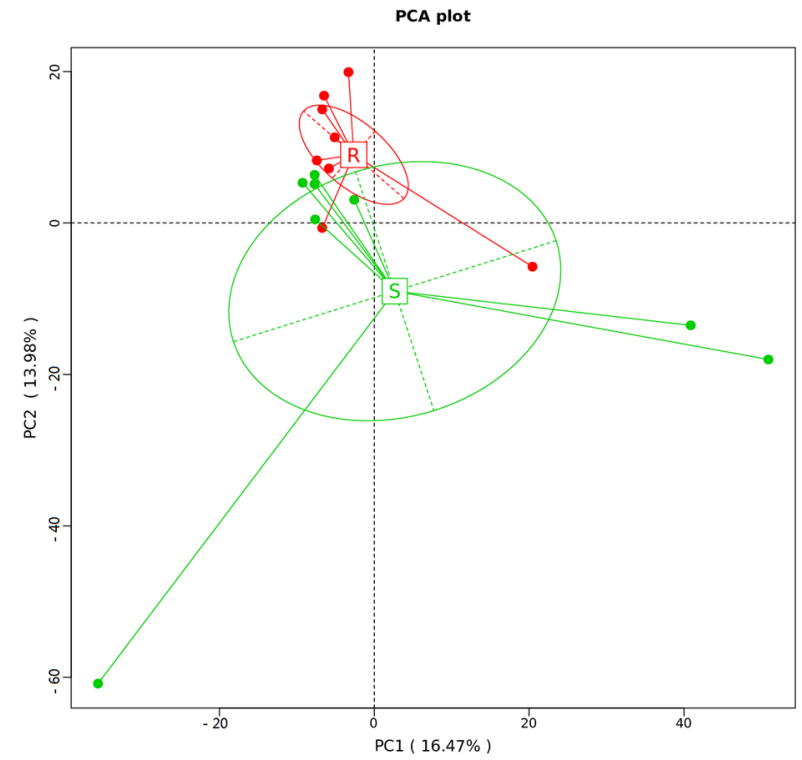

(a)

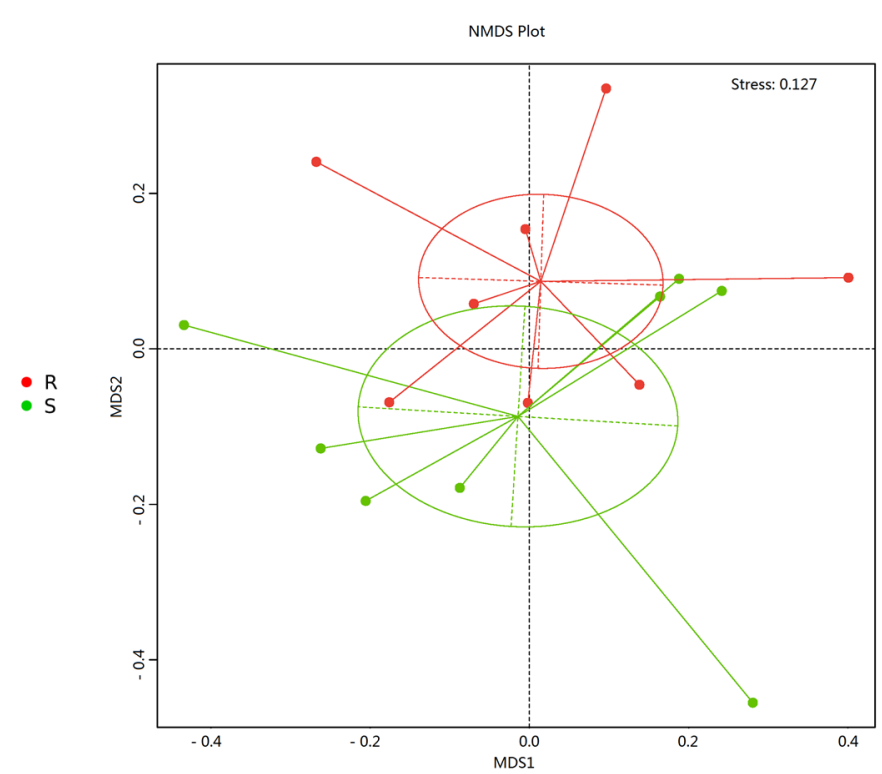

(b)

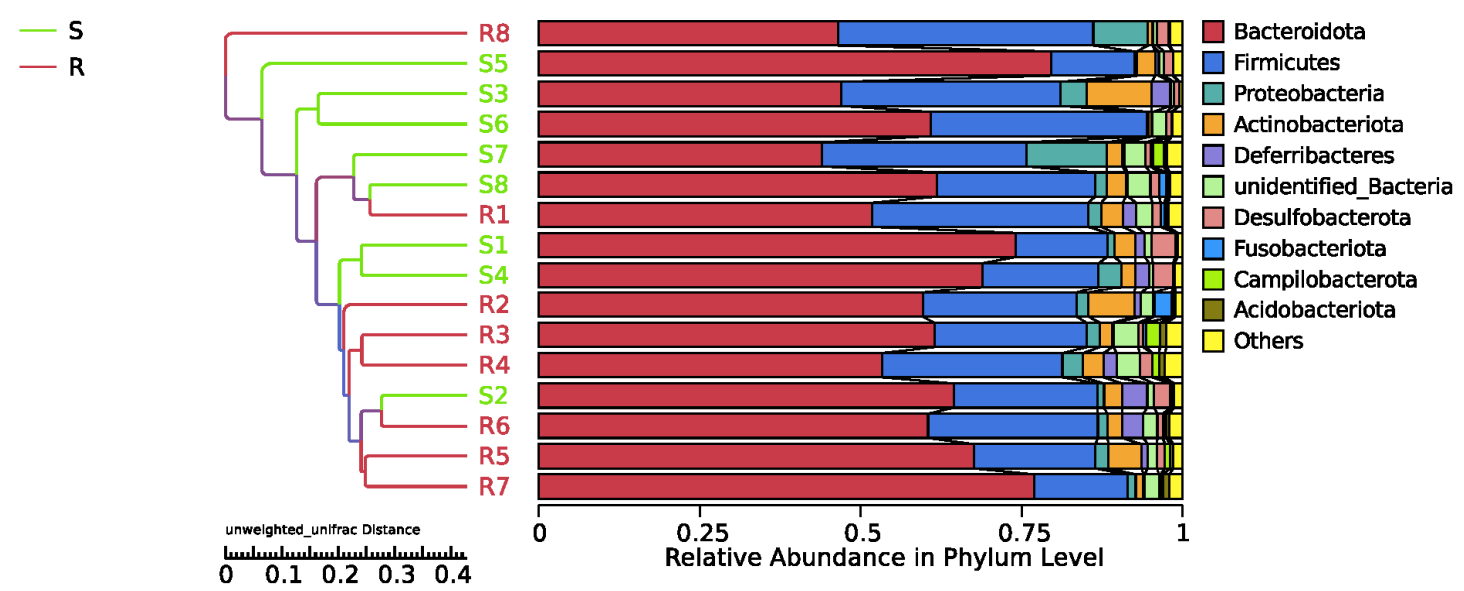

(c)

Figure 3. Beta diversity analysis of cecal microbiota $(n=8)$. (a) Principal component analysis (PCA). (b) Non-metric multidimensional scaling (NMDS). (c) Unweighted pair-group method with arithmetic means (UPGMA) clustering tree structure. $\mathrm{R}=$ S. enteritidis-resistant chicks; $\mathrm{S}=$ S. enteritidis-susceptible chicks.

Data for the top 10 microbial populations of the cecal bacterial community were analyzed at the phylum level. As shown in Figure 4a, Bacteroidota, Firmicutes, Proteobacteria, and Actinobacteriota $(59.73 \%$ vs. $62.60 \%, 26.07$ vs. $23.97 \% \%, 2.81 \%$ vs. $3.08 \%$, and $3.10 \%$ vs. $3.36 \%$, for group $\mathrm{S}$ vs. group R, respectively) constituted the four dominant phyla in both groups of chicks. Among the top 10 microbial populations, the relative abundance of Acidobacteriata, Campilobacterota, and Fusobacteriota in group $\mathrm{R}$ was lower than that in group $\mathrm{S}$ (Wilcoxon test, $p<0.05$ ) (Figure 4c). 


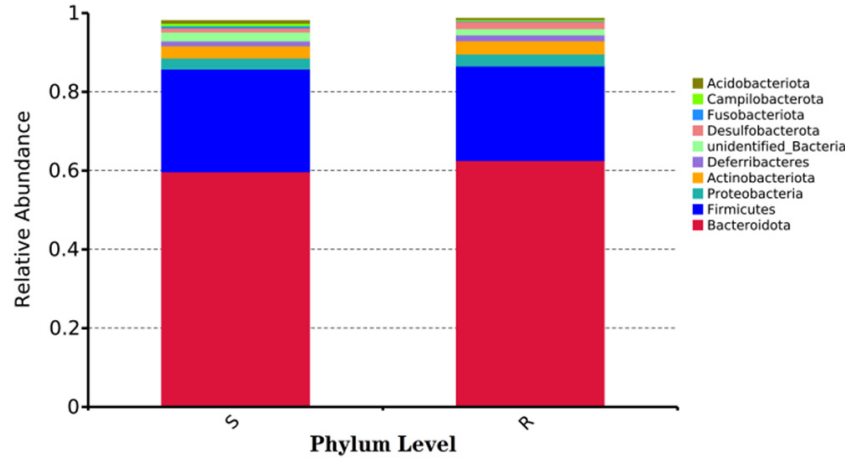

(a)

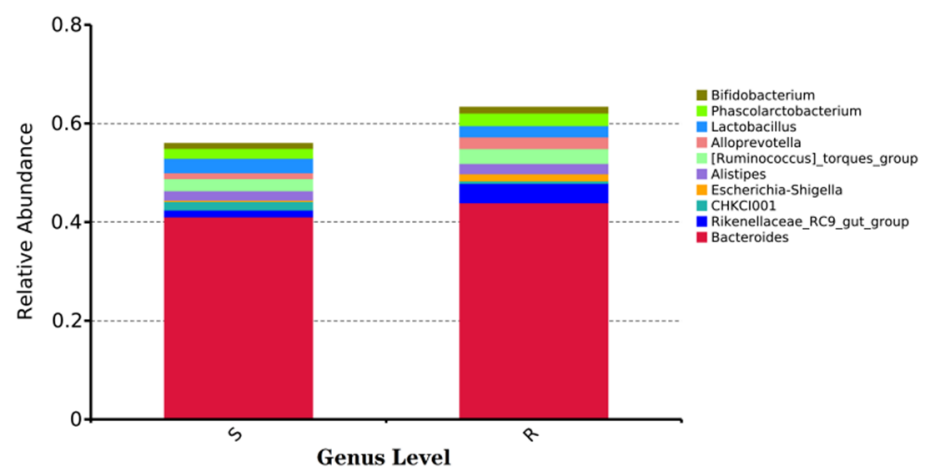

(b)

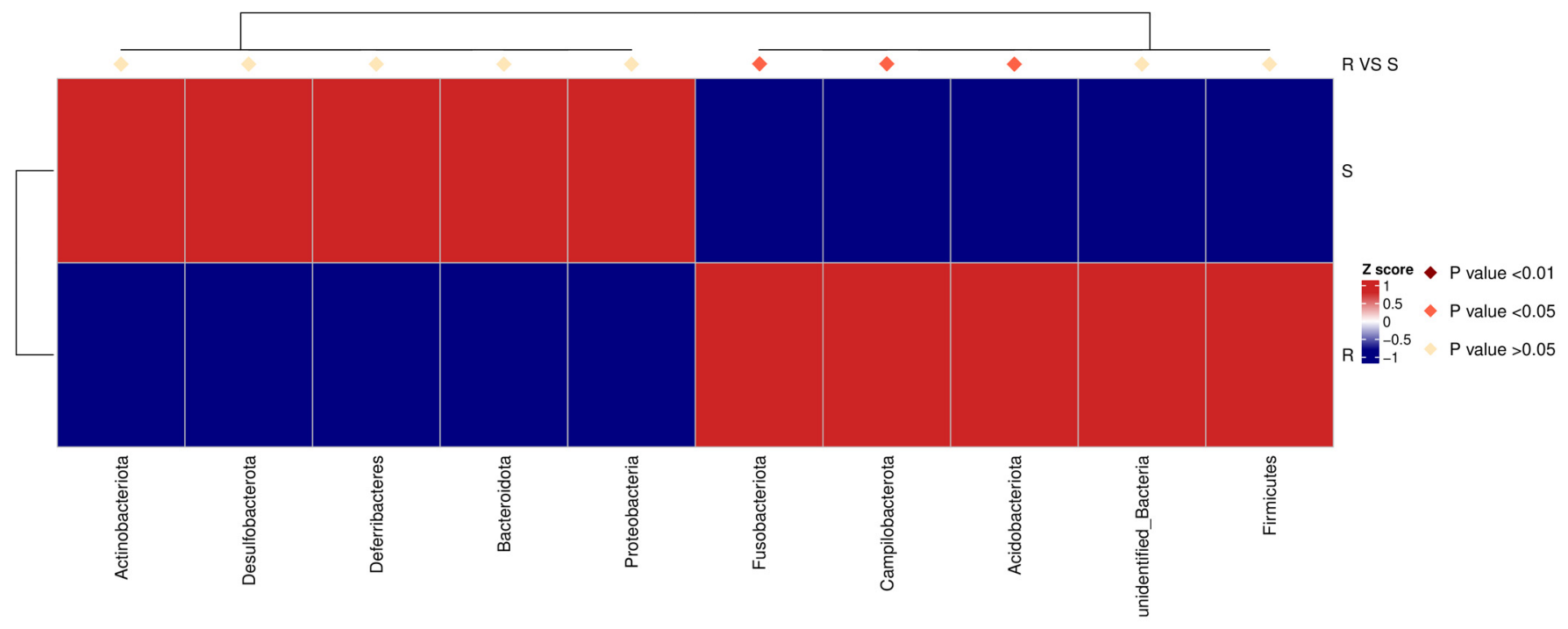

(c)

Figure 4. Changes in microbial composition and structure at the phylum and genus levels $(n=8)$. (a) Top 10 microbial populations at the phylum level. (b) Top 10 microbial populations at the genus level. S = selected S. enteritidis-susceptible chicks; $\mathrm{R}=$ selected S. enteritidis-resistant chicks. (c) Complex heatmap of the top 10 microbial populations at the phylum level.

At the genus level, the top 10 genera of the cecal bacterial community (Figure $4 \mathrm{~b}$ ) did not differ significantly between the two groups. Differentiation analysis was also conducted on other identified low-abundance genera. As shown in Table 5, a total of 18 genera showed significantly different abundance between group $\mathrm{S}$ and group R. Among them, Fusobacterium, Helicobacter, Butyricicoccus, Bryobacter, Acidothermus, unidentified_Chloroplast, NK4A214_group, Marvinbryantia, Burkholderia-Caballeronia-Paraburkholderia, Granulicella, Puia, unidentified_IMCC26256, Actinospica, Dyella, and Nocardia had higher abundance in group S than those in group R; while Oribacterium, Herbinix, and Papillibacter had lower abundance in group $\mathrm{S}$ than that of group $\mathrm{R}$ (Wilcoxon test, $p<0.05$ ).

To identify differentially abundant biomarkers in S. enteritidis-susceptible and -resistant chicks, we employed LEfSe (Figure 5). A cladogram representative of the structure of the microbial communities and their predominant bacteria is shown in Figure 5a. Only taxa with linear discriminant analysis (LDA) values greater than 3 are shown for clarity (Figure 5b). At the phylum level, Acidobacteriota, Campilobacteriota, Fusobacteriota, and Kapabacteria were enriched in group S (green circles). At the class level, Acidobacteria, Campilobacteria, and Fusobacteriia were enriched in group S. At the order level, Campylobacterales, Fusobacteriales and Kapabacteriales were enriched in group S and VeillonellalesSelenomonadales were prevalent in group R (red circle). At the family level, Barnesiellaceae, Helicobacteraceae, Butyricicoccaceae, and Fusobacteriaceae were enriched in group S. Three 
genera (Fusobacterium, Helicobacter, and Butycicoccus) had higher LDA scores in group S. Two species (Helicobacter_pullorum and Bacteroides_caecicola) had higher LDA scores in group S; one specie (Desulfovibrio_piger) had a higher LDA score in group R.

Table 5. Genera with significant differences between S. enteritidis-susceptible and -resistant chicks ${ }^{1}$.

\begin{tabular}{|c|c|c|c|}
\hline Taxa & Group S (\%) ${ }^{2}$ & Group R (\%) ${ }^{2}$ & $p$-Value \\
\hline Fusobacterium & $0.5168 \pm 0.9028^{a}$ & $0.1782 \pm 0.3837^{\mathrm{b}}$ & 0.043 \\
\hline Helicobacter & $0.6998 \pm 0.6460^{\mathrm{a}}$ & $0.3238 \pm 0.5453^{b}$ & 0.028 \\
\hline Butyricicoccus & $0.8835 \pm 0.5888^{a}$ & $0.3974 \pm 0.4655^{b}$ & 0.050 \\
\hline Bryobacter & $0.1440 \pm 0.1037^{\mathrm{a}}$ & $0.0426 \pm 0.0371^{b}$ & 0.034 \\
\hline Acidothermus & $0.1222 \pm 0.0886^{\mathrm{a}}$ & $0.0224 \pm 0.0251^{b}$ & 0.026 \\
\hline unidentified_Chloroplast & $0.0637 \pm 0.0814^{\mathrm{a}}$ & $0.0256 \pm 0.0469^{b}$ & 0.039 \\
\hline NK4A214_group & $0.0560 \pm 0.0504^{\mathrm{a}}$ & $0.0214 \pm 0.0243^{b}$ & 0.040 \\
\hline Marvinbryantia & $0.0685 \pm 0.0414^{\mathrm{a}}$ & $0.0278 \pm 0.0272^{b}$ & 0.046 \\
\hline Burkholderia-Caballeronia-Paraburkholderia & $0.0525 \pm 0.0394^{\mathrm{a}}$ & $0.0112 \pm 0.0166^{\mathrm{b}}$ & 0.024 \\
\hline Granulicella & $0.0458 \pm 0.0352^{\mathrm{a}}$ & $0.0096 \pm 0.0130^{b}$ & 0.035 \\
\hline Puia & $0.0218 \pm 0.0228^{\mathrm{a}}$ & $0.0035 \pm 0.0056^{\mathrm{b}}$ & 0.048 \\
\hline Oribacterium & $0.0013 \pm 0.0036^{b}$ & $0.0102 \pm 0.0162^{\mathrm{a}}$ & 0.028 \\
\hline unidentified_IMCC26256 & $0.0182 \pm 0.0134^{\mathrm{a}}$ & $0.0042 \pm 0.0067^{b}$ & 0.037 \\
\hline Actinospica & $0.0102 \pm 0.0092^{\mathrm{a}}$ & $0.0013 \pm 0.0024^{b}$ & 0.021 \\
\hline Herbinix & $0^{b}$ & $0.0064 \pm 0.0079^{\mathrm{a}}$ & 0.013 \\
\hline Dyella & $0.0074 \pm 0.0079^{\mathrm{a}}$ & $0.0010 \pm 0.0019^{b}$ & 0.037 \\
\hline Nocardia & $0.0061 \pm 0.0056^{\mathrm{a}}$ & $0.0006 \pm 0.0018^{b}$ & 0.017 \\
\hline Papillibacter & $0.0003 \pm 0.0009^{b}$ & $0.0041 \pm 0.0034^{\mathrm{a}}$ & 0.034 \\
\hline
\end{tabular}

${ }^{1}$ Results are expressed as means \pm SEM, with $n=8$ per group. ${ }^{2}$ Group $\mathrm{S}=$ selected $S$. enteritidis-susceptible chicks; Group $\mathrm{R}=$ selected S. enteritidis-resistant chicks. ${ }^{\mathrm{a}, \mathrm{b}}$ In the same row, values with different letters are significantly different between 2 groups $(p<0.05)$.

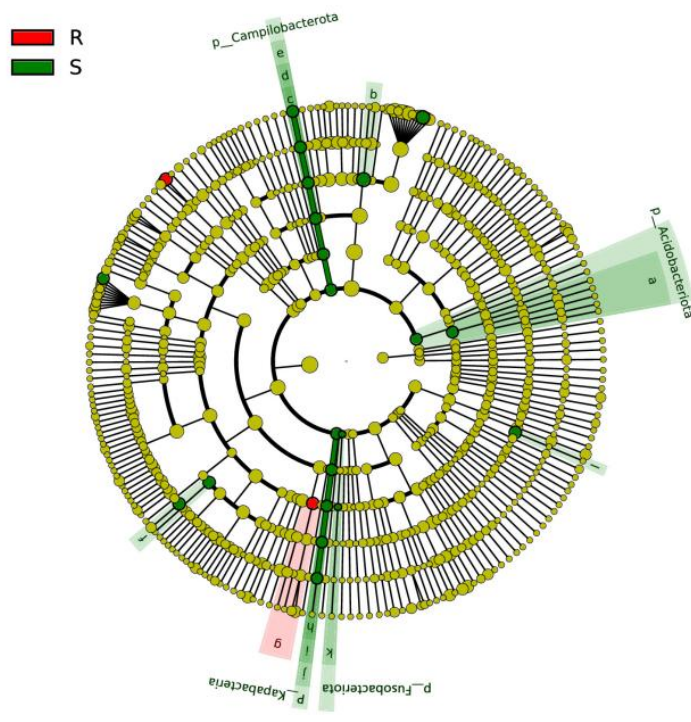

(a)

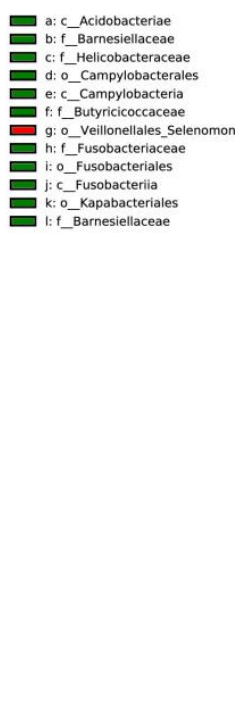

$-4-3$

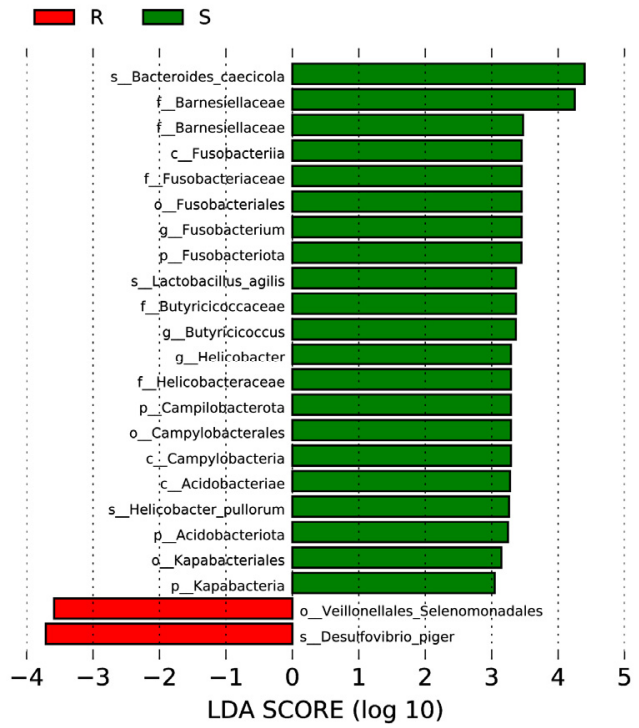

(b)

Figure 5. Linear discriminant analysis effect size (LEfSe) identified the most differentially abundant taxa between group $\mathrm{S}$ (green bars) and group R (red bars). (a) Taxonomic cladogram obtained from LEfSe analysis of 16S rRNA gene sequences. Small circles and shading with different colors in the diagram represent the abundance of those taxa in the respective group. Green circles represent taxa enriched in group S (green legend); Red circles represent taxa enriched in group $\mathrm{R}$ (red legend); Yellow circles represent non-significant differences in abundance between two groups. The brightness of each circle is proportional to its effect size. (b) Taxa enriched in group S are indicated with a positive LDA score (green), and taxa enriched in group R have a negative LDA score (red). Only those taxa with an LDA value greater than 3 are shown. 


\section{Discussion}

Salmonella can be transmitted horizontally to chickens from contaminated environmental vectors and vertically from infected hens to offspring. In this study, 1-d-old female AA female chicks, with Salmonella infection excluded by cloacal swab testing, were reared and challenged under the same conditions, therefore eliminating the influence of genetic background and environment on the experimental results to the greatest extent, and ensured that all the phenotypic results obtained in this study were due to individual differences. S. enteritidis mainly colonizes the liver, spleen, and intestine of poultry after infection [41,42], leading to intestinal damage, a decline in growth performance, and even death. Growth performance, pathological changes in organs, Salmonella loads, and intestinal morphology are important indicators of the severity of S. enteritidis infection. In this study, compared with S. enteritidis-resistant chicks, the livers of S. enteritidis-susceptible chicks became swollen (Table 3 ) and displayed salient lesions (Figure 1b). In addition, Salmonella loads in the liver and spleen of S. enteritidis-susceptible chicks were significantly higher than those of S. enteritidis-resistant chicks (Table 3). The VCR showed an increasing trend in chicks of group R than in chicks of group S (Table 4). These results indicated that our grouping scheme, i.e., selecting chicks with differential S. enteritidis susceptibility, was appropriate, and confirmed the heterogeneous nature of the response of the birds to S. enteritidis infection.

The intestinal mucosal barrier serves as the first line of defense between the host and the luminal environment. Composed of epithelial cells and tight junctions, this barrier can prevent the entry of harmful substances, such as pathogens and toxins, into host tissues, organs, and circulating blood [43]. The intestinal epithelium is involved in the formation of the intestinal mucosal barrier by continuously secreting MUC2 to renew the intestinal mucosal layer. Impaired intestinal mucosal barrier function is a key determinant of the pathogenicity of some intestinal bacteria. Studies have shown that Salmonella infection can disrupt the intestinal barrier of broilers, and promoting the expression of tight junction proteins through L-arginine supplementation can alleviate Salmonella infection, indicating that there is a negative correlation between intestinal barrier function and the severity of Salmonella infection [40]. In this study, we compared the expression of genes encoding tight junction proteins and MUC2 in S. enteritidis-susceptible and S. enteritidis-resistant chicks. The results showed that the mRNA expression of occludin and MUC2 in the jejunum of S. enteritidis-resistant chicks was significantly higher than that of S. enteritidis-susceptible chicks, further supporting that a negative correlation exists between intestinal mucosal barrier function and S. enteritidis susceptibility.

Because proinflammatory cytokines are essential for initiating immune responses and eliminating pathogens in the host, we hypothesized that chicks in group R would exhibit higher levels of inflammation than those of group $S$, therefore explaining the greater resistance of the birds in group $\mathrm{R}$ to $S$. enteritidis infection at the same dose of S. enteritidis challenge. However, our results showed that there was no significant difference in the expression of most proinflammatory factor-related genes between the two groups. Furthermore, the gene expression of $i N O S$ and IL6 showed the opposite trend to what would be expected, i.e., the expression of both genes was significantly higher in group $\mathrm{S}$ than in group R, whereas that of IL10, coding for an anti-inflammatory factor, was significantly lower. These results suggested that inflammatory cytokines may play a role in the heterogeneous responses in an unexpected way. Or the higher expression levels of proinflammatory cytokine-related genes may also be considered to be a phenotype of $S$. enteritidis-susceptible chicks, which is consistent with the results of the histopathological analysis of liver tissue. In addition, although $i N O S$ is believed to help cells resist bacterial invasion through the production of a large amount of NO, which serves as an antibacterial [44], it is notable that the relationship between $\mathrm{NO}$ and Salmonella in the host may not be merely antagonistic. It has been reported that Salmonella needs $\mathrm{NO}$ as a nitrogen source for nitrate respiration, and a low NO concentration is indispensable for promoting Salmonella growth [45]. This 
may also explain why the invasion of $S$. enteritidis in birds of group $\mathrm{S}$ was more severe, but their expression of the $i N O S$ gene were higher in our research.

In the chicken, the intestinal microbiota is composed of complex microbial communities that are involved in digestion and metabolism, the regulation of intestinal cells, vitamin synthesis, and the development and regulation of the host immune system [46]. There is also accumulating evidence indicating that the intestinal microbiota profoundly influences the pathogenicity of S. enteritidis [24]. Because the cecum is the most densely colonized microbial habitat in the chicken [47], we systematically compared the cecal microbial composition of chicks from the different $S$. enteritidis susceptibility groups. Alpha diversity refers to the richness and diversity within a microbial community in individual samples [48], whereas beta diversity is a comparative analysis of microbial community composition in different samples. Although no significant difference was recorded for alpha diversity, significant differences in beta diversity were observed between the cecal samples of the two groups, which agreed with previous results showing that Salmonella infection can lead to changes in cecal microbiota [21].

The cecal microbial composition of the two groups at both the phylum and genus levels was analyzed using the Wilcoxon test. The results showed that at the phylum level, the relative abundance of Acidobacteria, Campilobacterota, and Fusobacteriota were enriched in group S. The same results were obtained using LEfSe. At the genus level, 18 genera were identified as significantly differential microorganisms by the Wilcoxon test. Among them, Fusobacterium, Helicobacter, and Butycicoccus were identified as marker microorganisms in group S using LEfSe. As we know, Fusobacterium has been associated with gastric ulcers in pigs [49] and colon carcinoma in humans [50,51], and may represent a kind of new opportunistic pathogens of chickens worthy of further investigation [52]. In addition, in the species level, Helicobacter_pullorum has also been identified as a marker microorganism of group S, which is member of Campilobacterota and a well-known zoonotic pathogen [53]. These results revealed that chicks showing higher $S$. enteritidis resistance has lower abundance of pathogenic bacteria in their cecal.

Furthermore, we identified a marker microorganism, Desulfovibrio_piger, which was enriched in chicks of group R. Desulfovibrio_piger, belonging to Desulfovibrio spp., is a kind of sulfate reducing bacteria, which can functional reducing sulfate to hydrogen sulfide $\left(\mathrm{H}_{2} \mathrm{~S}\right)$ and plays an important role in intestinal hydrogen and sulfur metabolism. Although $\mathrm{H}_{2} \mathrm{~S}$ has been found to have dichotomous effects (stimulatory and inhibitory) on several gastrointestinal processes, it seems to be hazardous at high concentrations but favorable at low concentrations, and the overarching effect of $\mathrm{H}_{2} \mathrm{~S}$ appears to be beneficial. For example, $\mathrm{H}_{2} \mathrm{~S}$ can attenuate DSS-induced colitis, lessen the shortening of the colon lengths and colonic pathological damages, showing an overall protective effect in colitis via its anti-inflammatory properties [54]. In addition, ATB-429, an $\mathrm{H}_{2} \mathrm{~S}$ releasing derivative of mesalamine, exhibits a marked increase in anti-inflammatory activity and potency in a murine model of colitis, as compared to mesalamine, seems promising in the treatment of inflammatory bowel disease [55]. Our results were consistent with these above reports, as our chicks in group $\mathrm{R}$ showed higher abundance of Desulfovibrio_piger and lower inflammation response at the same time. However, whether Desulfovibrio_piger can really help chicks to resist the infection of $S$. enteritidis by producing $\mathrm{H}_{2} \mathrm{~S}$ still need to be verified.

\section{Conclusions}

In conclusion, our results confirmed that chicks showed heterogeneous responses to S. enteritidis infection, including different degrees of Salmonella loads in tissues, different tissue lesion severity, and distinct inflammatory responses. Our findings suggested that enhanced intestinal barrier function and cecal microbiota structure, especially a higher abundance of Desulfovibrio_piger, may help chicks resist S. enteritidis invasion. 
Supplementary Materials: The following are available online at https:/ / www.mdpi.com/article/ 10.3390/microorganisms9081705/s1, Table S1: Tissue Salmonella loads of all slaughtered chicks $(n=48)$, Table S2: Details of sequencing data, Table S3: Alpha diversity analysis of cecal microbiota $(n=8)$, Table S4: Beta diversity analysis of cecal microbiota $(n=8)$, Figure S1: Rarefaction curves of the observed OTUs.

Author Contributions: S.W., X.H. and S.S. designed the experiment, analyzed the data and wrote the manuscript; G.C., Q.Z., H.Y., Z.W. and K.K. participated the animal feeding and laboratory testing. All authors have read and agreed to the published version of the manuscript.

Funding: This research was funded by The National Natural Science Foundation of China (No. 31972587), the Natural Science Foundation of Jiangsu Province (No. BK20201482), the Jiangsu Provincial Key Laboratory of Poultry Genetics \& Breeding (JQLAB-ZZ-201903), and the Support Project for Scientific and Technical Talents in Hunan Province (2020TJ-Q02).

Institutional Review Board Statement: The study was conducted according to the Regulations of the Experimental Animal Administration issued by the State Committee of Science and Technology of the People's Republic of China, and approved by the Animal Care and Use Committee of the Poultry Institute, Chinese Academy of Agriculture Science (CNP20201030; 30 October 2020).

Informed Consent Statement: Not applicable.

Data Availability Statement: These sequence data have been submitted to the Biotechnology Information (NCBI) Sequence Read Archive databases under accession number PRJNA742372.

Acknowledgments: The authors acknowledge the support of the National Natural Science Foundation of China (No. 31972587), the Natural Science Foundation of Jiangsu Province (No. BK20201482), the Jiangsu Provincial Key Laboratory of Poultry Genetics \& Breeding (JQLAB-ZZ-201903), and the Support Project for Scientific and Technical Talents in Hunan Province (2020TJ-Q02).

Conflicts of Interest: The authors declare no conflict of interest.

\section{References}

1. Shi, S.; Wu, S.; Shen, Y.; Zhang, S.; Xiao, Y.; He, X.; Gong, J.; Farnell, Y.; Tang, Y.; Huang, Y.; et al. Iron oxide nanozyme suppresses intracellular Salmonella enteritidis growth and alleviates infection in vivo. Theranostics 2018, 8, 6149-6162. [CrossRef]

2. WHO. Salmonella (Non-Typhoidal). 2018. Available online: http://www.who.int/mediacentre/factsheets/fs139/en/ (accessed on 20 February 2018).

3. Jiang, M.; Zhu, F.; Yang, C.; Deng, Y.; Kwan, P.S.L.; Li, Y.; Lin, Y.; Qiu, Y.; Shi, X.; Chen, H.; et al. Whole-genome analysis of Salmonella enterica serovar enteritidis isolates in outbreak linked to online food delivery, Shenzhen, China, 2018. Emerg. Infect. Dis. 2020, 26, 789-792. [CrossRef] [PubMed]

4. $\quad$ Smith, A.M.; Tau, N.P.; Ngomane, H.M.; Sekwadi, P.; Ramalwa, N.; Moodley, K.; Govind, C.; Khan, S.; Archary, M.; Thomas, J. Whole-genome sequencing to investigate two concurrent outbreaks of Salmonella enteritidis in South Africa, 2018. J. Med. Microbiol. 2020, 69, 1303-1307. [CrossRef]

5. Sher, A.A.; Mustafa, B.E.; Grady, S.C.; Gardiner, J.C.; Saeed, A.M. Outbreaks of foodborne Salmonella enteritidis in the United States between 1990 and 2015: An analysis of epidemiological and spatial-temporal trends. Int. J. Infect. Dis. 2021, $105,54-61$. [CrossRef]

6. Shah, D.H.; Paul, N.C.; Sischo, W.C.; Crespo, R.; Guard, J. Population dynamics and antimicrobial resistance of the most prevalent poultry-associated Salmonella serotypes. Poult. Sci. 2017, 96, 687-702. [CrossRef]

7. Steed, A.L.; Christophi, G.P.; Kaiko, G.E.; Sun, L.; Goodwin, V.M.; Jain, U.; Esaulova, E.; Artyomov, M.N.; Morales, D.J.; Holtzman, M.J.; et al. The microbial metabolite desaminotyrosine protects from influenza through type I interferon. Science 2017, 357, 498-502. [CrossRef]

8. Sanchez, K.K.; Chen, G.Y.; Schieber, A.M.P.; Redford, S.E.; Shokhirev, M.N.; Leblanc, M.; Lee, Y.M.; Ayres, J.S. Cooperative metabolic adaptations in the host can favor asymptomatic infection and select for attenuated virulence in an enteric pathogen. Cell 2018, 175, 146-158. [CrossRef]

9. Velge, P.; Cloeckaert, A.; Barrow, P. Emergence of Salmonella epidemics: The problems related to Salmonella enterica serotype enteritidis and multiple antibiotic resistance in other major serotypes. Vet. Res. 2005, 36, 267-288. [CrossRef]

10. Calenge, F.; Kaiser, P.; Vignal, A.; Beaumont, C. Genetic control of resistance to salmonellosis and to Salmonella carrier-state in fowl: A review. Genet. Sel. Evol. 2010, 42, 11. [CrossRef]

11. Chaussé, A.M.; Grépinet, O.; Bottreau, E.; Vern, L.Y.; Menanteau, P.; Trotereau, J.; Robert, V.; Wu, Z.; Kerboeuf, D.; Beaumont, C.; et al. Expression of Toll-like receptor 4 and downstream effectors in selected cecal cell subpopulations of chicks resistant or susceptible to Salmonella carrier state. Infect. Immun. 2011, 79, 3445-3454. [CrossRef] 
12. Lawley, T.D.; Bouley, D.M.; Hoy, Y.E.; Gerke, C.; Relman, D.A.; Monack, D.M. Host transmission of Salmonella enterica serovar Typhimurium is controlled by virulence factors and indigenous intestinal microbiota. Infect. Immun. 2008, 76, 403-416. [CrossRef]

13. Menanteau, P.; Kempf, F.; Trotereau, J.; Virlogeux-Payant, I.; Gitton, E.; Dalifard, J.; Gabriel, I.; Rychlik, I.; Velge, P. Role of systemic infection, cross contaminations and super-shedders in Salmonella carrier state in chicken. Environ. Microbiol. 2018, 20, 3246-3260. [CrossRef]

14. Brown, R.L.; Clarke, T.B. The regulation of host defences to infection by the microbiota. Immunology 2017, 150, 1-6. [CrossRef]

15. Flemer, B.; Warren, R.D.; Barrett, M.P.; Cisek, K.; Das, A.; Jeffery, I.B.; Hurley, E.; O'Riordain, M.; Shanahan, F.; O’Toole, P.W. The oral microbiota in colorectal cancer is distinctive and predictive. Gut 2018, 67, 1454-1463. [CrossRef]

16. Masetti, G.; Moshkelgosha, S.; Köhling, H.L.; Covelli, D.; Banga, J.P.; Berchner-Pfannschmidt, U.; Horstmann, M.; Diaz-Cano, S.; Goertz, G.E.; Plummer, S.; et al. Gut microbiota in experimental murine model of Graves' orbitopathy established in different environments may modulate clinical presentation of disease. Microbiome 2018, 6, 97. [CrossRef]

17. Jie, Z.; Xia, H.; Zhong, S.L.; Feng, Q.; Li, S.; Liang, S.; Zhong, H.; Liu, Z.; Gao, Y.; Zhao, H.; et al. The gut microbiome in atherosclerotic cardiovascular disease. Nat. Commun. 2017, 8, 845. [CrossRef]

18. Zhao, L.; Zhang, F.; Ding, X.; Wu, G.; Lam, Y.Y.; Wang, X.; Fu, H.; Xue, X.; Lu, C.; Ma, J.; et al. Gut bacteria selectively promoted by dietary fibers alleviate type 2 diabetes. Science 2018, 359, 1151-1156. [CrossRef]

19. Cho, I.; Blaser, M.J. The human microbiome: At the interface of health and disease. Nat. Rev. Genet. 2012, 13, 260-270. [CrossRef]

20. Juricova, H.; Videnska, P.; Lukac, M.; Faldynova, M.; Babak, V.; Havlickova, H.; Sisak, F.; Rychlik, I. Influence of Salmonella enterica serovar enteritidis infection on the development of the cecum microbiota in newly hatched chicks. Appl. Environ. Microbiol. 2013, 79, 745-747. [CrossRef]

21. Borewicz, K.A.; Kim, H.B.; Singer, R.S.; Gebhart, C.J.; Sreevatsan, S.; Johnson, T.; Isaacson, R.E. Changes in the porcine intestinal microbiome in response to infection with Salmonella enterica and Lawsonia intracellularis. PLoS ONE 2015, 10, e0139106. [CrossRef]

22. Pollock, J.; Hutchings, M.R.; Hutchings, K.E.K.; Gally, D.L.; Houdijk, J.G.M. Changes in the ileal, but not fecal, microbiome in response to increased dietary protein level and enterotoxigenic Escherichia coli exposure in pigs. Appl. Environ. Microbiol. 2019, 85, e01252-19. [CrossRef]

23. Pickard, J.M.; Zeng, M.Y.; Caruso, R.; Núñez, G. Gut microbiota: Role in pathogen colonization, immune responses, and inflammatory disease. Immunol. Rev. 2017, 279, 70-89. [CrossRef]

24. Litvak, Y.; Mon, K.K.Z.; Nguyen, H.; Chanthavixay, G.; Liou, M.; Velazquez, E.M.; Kutter, L.; Alcantara, M.A.; Byndloss, M.X.; Tiffany, C.R.; et al. Commensal Enterobacteriaceae protect against Salmonella colonization through oxygen competition. Cell Host. Microbe 2019, 25, 128-139. [CrossRef] [PubMed]

25. Sabry, M.A.; Abdel-Moein, K.A.; Abdel-Kader, F.; Hamza, E. Extended-spectrum $\beta$-lactamase-producing Salmonella serovars among healthy and diseased chickens and their public health implication. J. Glob. Antimicrob. Resist. 2020, 22, 742-748. [CrossRef] [PubMed]

26. Zhang, S.; Shen, Y.; Wu, S.; Xiao, Y.; He, Q.; Shi, S. The dietary combination of essential oils and organic acids reduces Salmonella enteritidis in challenged chicks. Poult. Sci. 2019, 98, 6349-6355. [CrossRef] [PubMed]

27. Shen, Y.; Xiao, Y.; Zhang, S.; Wu, S.; Gao, L.; Shi, S. $\mathrm{Fe}_{3} \mathrm{O}_{4}$ nanoparticles attenuated Salmonella infection in chicken liver through reactive oxygen and autophagy via PI3K/Akt/mTOR signaling. Front. Physiol. 2020, 10, 1580. [CrossRef] [PubMed]

28. Hu, Y.; Wang, L.; Shao, D.; Wang, Q.; Wu, Y.; Han, Y.; Shi, S. Selectived and reshaped early dominant microbial community in the cecum with similar proportions and better homogenization and species diversity due to organic acids as AGP alternatives mediate their effects on broilers growth. Front. Microbiol. 2020, 10, 2948. [CrossRef]

29. Sousa, B.F.; Silva, A.F.B.D.; Lima-Filho, J.V.; Agostinho, A.G.; Oliveira, D.N.; De Alencar, N.M.N.; De Freitas, C.D.T.; Ramos, M.V. Latex proteins downregulate inflammation and restores blood-coagulation homeostasis in acute Salmonella infection. Mem. Inst. Oswaldo Cruz 2020, 115, e200458. [CrossRef]

30. Guo, L.D.; Hyde, K.D.; Liew, E.C.Y. Identification of endophytic fungi from Livistona chinensis based on morphology and rDNA sequences. New Phytol. 2000, 147, 617-630. [CrossRef]

31. Yu, X.; Wu, X.; Qiu, L.; Wang, D.; Gan, M.; Chen, X.; Wei, H.; Xu, F. Analysis of the intestinal microbial community structure of healthy and long-living elderly residents in Gaotian Village of Liuyang City. Appl. Microbiol. Biotechnol. 2015, 99, 9085-9095. [CrossRef]

32. Caporaso, J.G.; Lauber, C.L.; Walters, W.A.; Berg-Lyons, D.; Lozupone, C.A.; Turnbaugh, P.J.; Fierer, N.; Knight, R. Global patterns of 16S rRNA diversity at a depth of millions of sequences per sample. Proc. Natl. Acad. Sci. USA 2011, 108 (Suppl. 1), $4516-4522$. [CrossRef] [PubMed]

33. Gao, Y.; Wang, C.; Zhang, W.; Di, P.; Yi, N.; Chen, C. Vertical and horizontal assemblage patterns of bacterial communities in a eutrophic river receiving domestic wastewater in southeast China. Environ. Pollut. 2017, 230, 469-478. [CrossRef] [PubMed]

34. Magoč, T.; Salzberg, S.L. FLASH: Fast length adjustment of short reads to improve genome assemblies. Bioinformatics 2011, 27, 2957-2963. [CrossRef] [PubMed]

35. Caporaso, J.G.; Kuczynski, J.; Stombaugh, J.; Bittinger, K.; Bushman, F.D.; Costello, E.K.; Fierer, N.; Peña, A.G.; Goodrich, J.K.; Gordon, J.I.; et al. QIIME allows analysis of high-throughput community sequencing data. Nat. Methods 2010, 7, 335-336. [CrossRef] 
36. Haas, B.J.; Gevers, D.; Earl, A.M.; Feldgarden, M.; Ward, D.V.; Giannoukos, G.; Ciulla, D.; Tabbaa, D.; Highlander, S.K.; Sodergren, E.; et al. Chimeric 16S rRNA sequence formation and detection in Sanger and 454-pyrosequenced PCR amplicons. Genome Res. 2011, 21, 494-504. [CrossRef]

37. Wang, Q.; Garrity, G.M.; Tiedje, J.M.; Cole, J.R. Naive Bayesian classifier for rapid assignment of rRNA sequences into the new bacterial taxonomy. Appl. Environ. Microbiol. 2007, 73, 5261-5267. [CrossRef]

38. Zhang, L.; Wu, W.; Lee, Y.K.; Xie, J.; Zhang, H. Spatial heterogeneity and co-occurrence of mucosal and luminal microbiome across swine intestinal tract. Front. Microbiol. 2018, 9, 48. [CrossRef] [PubMed]

39. Lozupone, C.; Knight, R. UniFrac: A new phylogenetic method for comparing microbial communities. Appl. Environ. Microbiol. 2005, 71, 8228-8235. [CrossRef]

40. Zhang, B.; Li, G.; Shahid, M.S.; Gan, L.; Fan, H.; Lv, Z.; Yan, S.; Guo, Y. Dietary l-arginine supplementation ameliorates inflammatory response and alters gut microbiota composition in broiler chickens infected with Salmonella enterica serovar Typhimurium. Poult. Sci. 2020, 99, 1862-1874. [CrossRef]

41. Shah, D.H.; Zhou, X.; Kim, H.Y.; Call, D.R.; Guard, J. Transposon mutagenesis of Salmonella enterica serovar enteritidis identifies genes that contribute to invasiveness in human and chicken cells and survival in egg albumen. Infect. Immun. 2012, 80, 4203-4215. [CrossRef]

42. Wang, C.L.; Fan, Y.C.; Wang, C.; Tsai, H.J.; Chou, C.H. The impact of Salmonella enteritidis on lipid accumulation in chicken hepatocytes. Avian. Pathol. 2016, 45, 450-457. [CrossRef]

43. König, J.; Wells, J.; Cani, P.D.; García-Ródenas, C.L.; MacDonald, T.; Mercenier, A.; Whyte, J.; Troost, F.; Brummer, R.J. Human intestinal barrier function in health and disease. Clin. Transl. Gastroenterol. 2016, 7, e196. [CrossRef] [PubMed]

44. Nathan, C.; Shiloh, M.U. Reactive oxygen and nitrogen intermediates in the relationship between mammalian hosts and microbial pathogens. Proc. Natl. Acad. Sci. USA 2000, 97, 8841-8848. [CrossRef]

45. Fu, Y.; Galán, J.E. A Salmonella protein antagonizes Rac-1 and Cdc42 to mediate host-cell recovery after bacterial invasion. Nature 1999, 401, 293-297. [CrossRef] [PubMed]

46. Khan, S.; Chousalkar, K.K. Salmonella Typhimurium infection disrupts but continuous feeding of Bacillus based probiotic restores gut microbiota in infected hens. J. Anim. Sci. Biotechnol. 2020, 11, 29. [CrossRef]

47. Pourabedin, M.; Zhao, X. Prebiotics and gut microbiota in chickens. FEMS. Microbiol. Lett. 2015, 362, fnv122. [CrossRef] [PubMed]

48. Li, B.; Zhang, X.; Guo, F.; Wu, W.; Zhang, T. Characterization of tetracycline resistant bacterial community in saline activated sludge using batch stress incubation with high-throughput sequencing analysis. Water. Res. 2013, 47, 4207-4216. [CrossRef]

49. De Witte, C.; Demeyere, K.; De Bruyckere, S.; Taminiau, B.; Daube, G.; Ducatelle, R.; Meyer, E.; Haesebrouck, F. Characterization of the non-glandular gastric region microbiota in Helicobacter suis-infected versus non-infected pigs identifies a potential role for Fusobacterium gastrosuis in gastric ulceration. Vet. Res. 2019, 50, 39. [CrossRef]

50. Mármol, I.; Sánchez-de-Diego, C.; Pradilla Dieste, A.; Cerrada, E.; Rodriguez Yoldi, M.J. Colorectal carcinoma: A general overview and future perspectives in colorectal cancer. Int. J. Mol. Sci. 2017, 18, 197. [CrossRef]

51. Rubinstein, M.R.; Baik, J.E.; Lagana, S.M.; Han, R.P.; Raab, W.J.; Sahoo, D.; Dalerba, P.; Wang, T.C.; Han, Y.W. Fusobacterium nucleatum promotes colorectal cancer by inducing Wnt/ $\beta$-catenin modulator Annexin A1. EMBO Rep. 2019, 20, e47638. [CrossRef]

52. Kollarcikova, M.; Kubasova, T.; Karasova, D.; Crhanova, M.; Cejkova, D.; Sisak, F.; Rychlik, I. Use of 16S rRNA gene sequencing for prediction of new opportunistic pathogens in chicken ileal and cecal microbiota. Poult. Sci. 2019, 98, 2347-2353. [CrossRef] [PubMed]

53. Javed, S.; Gul, F.; Javed, K.; Bokhari, H. Helicobacter pullorum: An emerging zoonotic pathogen. Front. Microbiol. 2017, 8, 604. [CrossRef] [PubMed]

54. Qin, M.; Long, F.; Wu, W.; Yang, D.; Huang, M.; Xiao, C.; Chen, X.; Liu, X.; Zhu, Y.Z. Hydrogen sulfide protects against DSS-induced colitis by inhibiting NLRP3 inflammasome. Free Radic. Biol. Med. 2019, 137, 99-109. [CrossRef] [PubMed]

55. Fiorucci, S.; Orlandi, S.; Mencarelli, A.; Caliendo, G.; Santagada, V.; Distrutti, E.; Santucci, L.; Cirino, G.; Wallace, J.L. Enhanced activity of a hydrogen sulphide-releasing derivative of mesalamine (ATB-429) in a mouse model of colitis. Br. J. Pharmacol. 2007, 150, 996-1002. [CrossRef] [PubMed] 